\title{
BMJ Open Factors affecting research utilisation of nurses and midwives working in North Gondar and West Gojjam Zone public hospitals, Ethiopia: a cross- sectional study
}

Asrat Hailu Dagne (D) ,' Mequannent Melaku Ayalew ${ }^{2}$

To cite: Dagne AH, Ayalew MM. Factors affecting research utilisation of nurses and midwives working in North Gondar and West Gojjam Zone public hospitals, Ethiopia: a cross-sectional study. BMJ Open 2020;10:e039586. doi:10.1136/ bmjopen-2020-039586

- Prepublication history for this paper is available online. To view these files, please visit the journal online (http://dx.doi org/10.1136/bmjopen-2020039586).

Received 21 April 2020 Revised 27 September 2020 Accepted 11 October 2020

\section{Check for updates}

(C) Author(s) (or their employer(s)) 2020. Re-use permitted under CC BY-NC. No commercial re-use. See rights and permissions. Published by BMJ.

${ }^{1}$ Midwifery, Debre Tabor University, Debre Tabor, Amhara Region, Ethiopia

${ }^{2} \mathrm{MPH} / \mathrm{RH}$, Bahir Dar University, Bahir Dar, Amhara, Ethiopia

Correspondence to

Asrat Hailu Dagne;

1221asrat@gmail.com

\section{ABSTRACT}

Background Research utilisation in clinical decisionmaking is crucial to enhance quality healthcare, professional development and cost-effective health service. Nurses and midwives have a vital role in research utilisation. However, many factors influence research utilisation of nurses and midwives.

Objectives To determine research utilisation and identify factors that affect research utilisation among nurses and midwives.

Methods An institutional-based, cross-sectional study was conducted from 23 May to 30 June 2019. A total of 631 nurses and midwives participated in the study. Categorical variables were coded with dummy variables and multiple linear regression model was carried out. The level of significance was set at $p$ value less than or equal to 0.05 with $95 \% \mathrm{Cl}$.

Results Participants' total mean score in the research utilisation scale was $2.27(\mathrm{SD} \pm 0.77)$ and their mean age was $28.41(\mathrm{SD} \pm 4.71)$ years. The study revealed that $70.4 \%$ (444) of participants had poor research utilisation. Self-efficacy in research utilisation skills $(B=0.86,95 \%$ $\mathrm{Cl} 0.75$ to 0.97 ), support for research utilisation $(\mathrm{B}=0.4$, $95 \% \mathrm{Cl} 0.25$ to 0.55 ), attitude ( $\mathrm{B}=0.23,95 \% \mathrm{Cl} 0.07$ to 0.38 ), barriers to research utilisation $(B=-0.63,95 \% \mathrm{Cl}$ -0.72 to -0.54$)$, nursing/midwifery work index $(B=0.07$, $95 \% \mathrm{Cl} 0.04$ to 0.11 ) and hospital's level of healthcare $(\mathrm{B}=4.5,95 \% \mathrm{Cl} 2.13$ to 6.9 ) were statistically significantly associated factors of research utilisation.

Conclusions This study revealed poor research utilisation among nurses and midwives. Barriers to research utilisation, supporting factors for research utilisation, attitude, self-efficacy in research utilisation skills, hospital's level of healthcare and nursing/midwifery work index were found to be statistically significant predictors of research utilisation. The most common barriers to research utilisation were insufficient time and inability to understand statistical terms used in research articles.

\section{BACKGROUND}

Research utilisation is defined as the integration of clinical expertise with the best currently available research evidence or external evidence from systematic research. ${ }^{1}$
Strengths and limitations of this study

- The study was conducted using face-to-face interview techniques, which contributed to a $100 \%$ response rate.

- Risk of bias was reduced by ensuring the privacy of participants during data collection.

- The study addresses research utilisation which is typically supported by reducing barriers to research utilisation, improving self-efficacy in research utilisation skills, increasing support for research utilisation, maximising positive attitude towards research utilisation, nursing/midwifery work index and hospital's level of healthcare.

- A limitation of this study was the possibility of social desirability bias as it was conducted while nurses and midwives were working in the hospitals.

- Qualitative design, which could strengthen the findings of this cross-sectional study, was not used.

Research utilisation in clinical decisionmaking practices has been increasing nowadays. There is growing knowledge, skills and attitude among nurses and midwives throughout the international community. Nurses and midwives are responsible for using the best available research findings in their professions. ${ }^{23}$ Research utilisation is considered to play a vital role in the provision of quality healthcare and patient safety management in health facilities. ${ }^{3}$ National and international organisations have been encouraging proper utilisation of research among quality healthcare professionals. Research utilisation also increases knowledge in formal and informal health information, anticipation of a new treatment and the role of patients in clinical decisionmaking practices. ${ }^{4}$ However, research utilisation in clinical decision-making is one of the challenges that nurses and midwives face. 
Therefore, research utilisation should be supported by investigating the continuing gap between research and practice. ${ }^{56}$

There is an excellent deal with the knowledge, skills, attitude of nurses and midwives towards research utilisation, organisational barriers of research utilisation, and research utilisation facilitator. ${ }^{2}{ }^{3}$ Nurses and midwives have positive attitude towards research utilisation and their practice should be based on evidence. ${ }^{67}$ Despite their awareness of the importance of research utilisation, majority of nurses and midwives do not integrate research findings into their practice. ${ }^{78}$ In a systematic review of 1144 barriers to research utilisation, it was indicated that organisational and individual categories of barriers are the most common barriers to research utilisation. ${ }^{9}{ }^{10}$ Mismanagement of time due to heavy workload, lack of resources, lack of motivation and lack of support for research utilisation are organisational barriers to research utilisation. ${ }^{9-11}$ Individual categories of barriers to research utilisation include perception, knowledge, skills, attitude and professional development. $^{910} 12$ Moreover, research utilisation in clinical decision-making seems to be at its infancy level and barriers vary between geographical settings. ${ }^{13} \mathrm{~A}$ common strategy to bridge the gap between clinical decision-making practices and research utilisation is to recognise the obstacles to using research in the clinical context. ${ }^{13}$ Studies have indicated that knowledge and skills of nurses and midwives are not sufficient when using research findings in clinical decision-making. ${ }^{2} 8$ Moreover, lack of culture in using research findings, mismanagement of time, lack of peer support, negative attitudes and self-efficacy in research utilisation skills are potential factors that affect research utilisation. ${ }^{1415}$

Capacity building of knowledge, skills and attitude of nurses and midwives ${ }^{1617}$ is acknowledged in most countries to overcome factors that affect research utilisation in clinical decision-making practices. ${ }^{14} 161819$ Although different studies on barriers to research utilisation have been conducted, there is no definite solution and sustainable research utilisation. ${ }^{3}{ }^{13}$ Robust and visible academic leadership, organisational demands and supportive infrastructures are necessary for capacity building and research utilisation. ${ }^{19} 20$ Therefore, nurses and midwives must lead in translating their knowledge into practice to develop quality and safe healthcare practices. ${ }^{21}$ The development of knowledge and skills of nurses and midwives as a result of clinical and academic cooperative network has an inherent power to increase quality of healthcare through research utilisation. ${ }^{17} 20$ Incorporating new knowledge is invaluable and it is a form of learning. ${ }^{22}$ Thus, organisational context plays a significant role in improving research utilisation of nurses and midwives. ${ }^{23}$

The knowledge, skills and attitude of nurses and midwives and the context-related factors of research utilisation are less studied in Ethiopia. A few validated questionnaires were used by the studies conducted in this country, and some factors such as training in research utilisation, nursing or midwifery work index and barriers to research utilisation were not studied. Elements that are specific to a particular context of research utilisation need to be identified. ${ }^{13}$ The study findings will provide an opportunity to identify factors that affect research utilisation based on the context of the study setting. The results will also serve as baseline to measure and monitor change in research utilisation readiness following tailored educational and organisational interventions. Therefore, this study was designed to determine research utilisation and identify factors that affect research utilisation among nurses and midwives.

\section{METHODS}

\section{Study design and setting}

A cross-sectional study was conducted from 23 May to 30 June 2019 among nurses and midwives working in North Gondar and West Gojjam Zone public hospitals. The two zones are administrative zones of the Amhara Region in Ethiopia. There are 17 hospitals in the zones, which include 2 referral hospitals (Felege Hiwot and Gondar), 2 general hospitals (Debark and Finote Selam) and 13 primary hospitals (Metema, Janamora, Wogera, Aykel, Abrhajira, Delgi, Sanja, Feresbet, Burie, Merawi, Durbetie, Addis Alem and Adet). These hospitals serve more than six million people, and the nurses and midwives working in these 17 hospitals were included in the study.

\section{Participants}

The 2 referral hospitals had 542 nurses and 129 midwives, the 2 general hospitals had 81 nurses and 35 midwives, and the 13 primary hospitals had 513 nurses and 91 midwives. Nurses and midwives holding a diploma were excluded due to the lack of research methodology and epidemiology in their curriculum. Those working in private health institutions were also excluded to avoid double counting, as it is possible that public health workers could also work part-time in private institutions. Participants who were ill and unable to respond during the study period were also excluded from the study. The sample size for this study was calculated using single population mean formula. The required sample size for this study was determined using the following assumptions: precision level $(w)=0.85$, confidence level $=95 \%(Z \alpha / 2=1.96$ value $)$ and $9.2 \mathrm{SD}$. Due to lack of a previous study, a pilot study was conducted to obtain SD and precision level for the study area. The calculated total sample size was 382.78. Considering a design effect of 1.5 , the sample size was 574 , and adding $10 \%$ non-response rate the final sample size was 631 .

The list of all nurses and midwives from each public hospital who were bachelor's degree and master's degree holders was used as a sampling frame to identify potential study participants. In terms of research 
utilisation, nurses and midwives working in the same hospital were homogeneous. Study participants were recruited using record identification numbers retrieved from the sampling frame. First, a proportionate stratified sampling technique was deployed to select participants from all public hospitals equally. Second, to select samples, a simple random sampling technique was conducted using the lottery method based on the proportion of the number of nurses and midwives working in each hospital.

\section{Instrument}

All questionnaires were developed following detailed literature examination. Valid and reliable instruments were considered from different literature. Questionnaires were first prepared in English and then translated to Amharic, which is the colloquial or mother tongue language of the respondents. Questionnaires were also retranslated back to English for consistency. Different items used to measure research utilisation, attitude towards research utilisation, self-efficacy in research utilisation skills, supporting factors for research utilisation, barriers to research utilisation and nurses/ midwives work index were considered. An overview of the measurement of the outcome and independent variables is stated as follows.

\section{Outcome variable}

The outcome variable is research utilisation, which is also considered a composite variable. Eighteen statements were developed by Gerrish et $a l^{24}$ while the Evidence-Based Practice Implementation Scale was developed by Melnyk et al. ${ }^{25}$ These questionnaires were used to assess the research utilisation of respondents on a 5-point frequency scale, by indicating how often in the past 8 weeks nurses and midwives performed each item on the questionnaire. Questionnaires are related to actual research utilisation; for example, how often did you use research within the last 8 weeks? or 'Did you use research findings to change your clinical practice within the last 8 weeks?'. The responses for each question was one alternative from $1=$ never ( 1 time before the eighth week), $2=$ rarely (1-3 times), $3=$ sometimes ( $4-6$ times), $4=$ often $(7-8$ times $)$ and $5=$ always $(>8$ times), with the total score ranging from 18 to 90 .

\section{Independent variables}

The questionnaire about the independent variables contains the following subsections: sociodemographic, organisation-related characteristics, self-efficacy in research utilisation skills, attitude towards research utilisation, nursing/midwifery work index, barriers to research utilisation and supporting factors for research utilisation. Questions about attitude, barriers to research utilisation, supporting factors for research utilisation and nursing/midwifery work index items were all answered with the following options: strongly agree, agree, neither agree nor disagree, disagree, and strongly disagree (on a 5-point Likert scale). ${ }^{26} 27$ There are 31 questions that assess the nursing/midwifery work index, with scores ranging 31 to 155 . Respondents' selfefficacy in research utilisation skills was assessed using nine questions, with the total scale score ranging from 9 to 45 . The questionnaire related to attitude contains six questions, with the total scale score ranging from 6 to 30 . The questionnaire on barriers to research utilisation also contains nine questions, with the total scale score ranging from 9 to 45 . The questionnaire on supporting factors for research utilisation contains six questions, with the total scale score ranging from 6 to 30. Five-point responses were scored from 1 to 5 and the mean scores were calculated. Mean scores below 3, 3-4 and above 4 were considered poor (unfavourable), moderate and desirable, respectively. ${ }^{27}$

\section{Data collection}

Data were collected via face-to-face interview techniques using semistructured questionnaires. Senior nurses and midwives, who had experience in data collection, participated in data collection. Training in research of 4 days' duration was given to six data collectors and four supervisors. The training focused on obtaining consent, maintaining neutrality, privacy issues, personal relation, ethics and questionnaire content to ensure consistency of data. The pretest was carried out before the actual data collection period among $64(10 \%)$ nurses and midwives working in Debre Tabor General Hospital. Based on the results of the pretest, items on the questionnaires that create confusion were corrected before the actual data collection. The content validity and internal reliability of each subsection of the questionnaires were assessed using Cronbach's alpha coefficient. The Cronbach's alpha of the different sections of the questionnaires was between 0.7 and 0.94 . The filled questionnaires were checked daily for completeness and consistency of responses to eliminate possible errors.

\section{Statistical analysis}

The investigators and supervisors coded and checked the data manually for completeness. Data were entered into EpiData V.3.1 and then exported to SPSS V.20 for statistical analysis. Descriptive statistics were used to present frequency tables of categorical variables, and continuous variables were presented as descriptive measures, expressed as mean and SD. Cronbach's alpha was used to measure reliability, mean, SD and interitem correlation of factors. A principal components analysis was employed to identify significant variables that explain the total variance of the factor. Categorical variables were coded with dummy variables. Bivariate analysis was used to identify correlations between variables. Multiple linear regression model was carried out and the level of significance was set at a $\mathrm{p}$ value equal to or less than 0.05 with $95 \%$ CI to identify the effects of sociodemographic, attitude, self-efficacy in research utilisation skills, barriers to research utilisation, supporting 
factors for research utilisation, nursing/midwifery work index and organisation-related factors on research utilisation. Independence, homoscedasticity, normality and linearity were checked using Durbin-Watson, through an association between residuals and typified prognosis using a histogram of typified residuals and partial regression graph, respectively.

\section{Consent to participate}

Formal letter of cooperation was written to West Gojjam and North Gondar Zone public hospitals. Permission to conduct the study was obtained from the medical director of each hospital. The participants were also briefed about the aims of the study and how to complete the questionnaire. They were assured that all information would remain confidential. Written informed consent was obtained from each study participant.

\section{Patient and public involvement}

The study was conducted among nurses and midwives (healthcare workers) only. Patients or the public were not involved in the design, or conduct, or reporting, or dissemination plans of our research. However, patients and the community were involved when the topic was selected as a priority problem. They will also be involved in the dissemination of the results or during interventions for identified gaps.

\section{Dissemination}

The results of this study will be disseminated to the Amhara Regional Health Bureau, Debre Tabor University, Amhara Region Hospitals, Amhara Regions zonal departments and other concerned bodies. The results of this study will be published in a peer-reviewed journal, and brief reports of findings will be directly presented to seminars, meetings and workshops.

\section{RESULTS}

\section{Sociodemographic characteristics}

The study involved 631 participants, with a response rate of $100 \%$. The mean age of the participants was 28.41 ( $\mathrm{SD} \pm 4.71)$ years. Majority of the participants $(70.7 \%)$ were between 20 and 29 years of age. Of the participants, $97.9 \%$ (618) were BSc nurse or midwives and 2.1\% (13) were MSc nurses or midwives. Of the participants, $10 \%$ were head nurses and midwives, $67.2 \%$ (424) were staff nurses and $22.8 \%$ (144) were staff midwives. The source of income for $97 \%$ of the participants was salary only, while for $3 \%$ the source of income was monthly salary and private business (private clinic and drug vendor). The frequency and percentage of the remaining sociodemographic characteristics are presented in table 1.

\section{Organisation-related factors}

With regard to training in research utilisation, 619 (98.1\%) nurses and midwives did not undergo training in using research as evidence. Of the total respondents, $10(1.6 \%)$ nurses and midwives had training in research
Table 1 Sociodemographic characteristics of nurses and midwives working in North Gondar and West Gojjam Zone public hospitals, North West Ethiopia, 2019

\begin{tabular}{|c|c|c|}
\hline Variables & $\begin{array}{l}\text { Frequency } \\
(\mathrm{N}=631)\end{array}$ & $\%$ \\
\hline \multicolumn{3}{|l|}{ Gender } \\
\hline Male & 349 & 55.3 \\
\hline Female & 282 & 44.7 \\
\hline \multicolumn{3}{|l|}{ Age } \\
\hline $20-24$ & 107 & 17.0 \\
\hline $25-29$ & 339 & 53.7 \\
\hline $30-34$ & 112 & 17.7 \\
\hline $35-54$ & 73 & 11.6 \\
\hline \multicolumn{3}{|l|}{ Marital status } \\
\hline Married & 292 & 46.3 \\
\hline Others & 339 & 53.7 \\
\hline \multicolumn{3}{|l|}{ Religion } \\
\hline Orthodox & 557 & 88.3 \\
\hline Others & 74 & 11.7 \\
\hline \multicolumn{3}{|l|}{ Ethnicity } \\
\hline Amhara & 589 & 93.3 \\
\hline Others & 42 & 6.7 \\
\hline \multicolumn{3}{|c|}{ Income per month (US\$) } \\
\hline $100-133$ & 125 & 19.8 \\
\hline $134-200$ & 195 & 30.9 \\
\hline $201-333$ & 165 & 26.2 \\
\hline$>333$ & 146 & 23.1 \\
\hline \multicolumn{3}{|c|}{ Years of experience } \\
\hline $1-5$ & 431 & 68.3 \\
\hline $6-10$ & 134 & 21.2 \\
\hline 11 and above & 66 & 10.5 \\
\hline \multicolumn{3}{|l|}{ Profession } \\
\hline Nurse & 477 & 75.6 \\
\hline Midwife & 154 & 24.4 \\
\hline
\end{tabular}

For marital status, others include single, widowed, separated and cohabited.

For religion, others include Muslim, Protestant, Catholic and Adventist.

For ethnicity, others include Oromo, Tigraye, Kimant, Agew, Wolaita, Sidamo and Gurage.

once within 5 years and $2(0.3 \%)$ had training two times within 5 years. In terms of hospital's level of healthcare, $48.2 \%$ (304), $8.4 \%$ (53) and $43.4 \%$ (274) of nurses and midwives were working in tertiary level healthcare (specialised hospitals), secondary level healthcare (general hospitals) and primary level healthcare (primary hospitals), respectively. Of the total participants, $169(26.8 \%)$ nurses were working in medical and surgical departments, 159 (25.2\%) nurses and midwives in obstetrics and gynaecology, 111 (17.6\%) nurses 
Table 2 Attitude of nurses and midwives towards research utilisation in North Gondar and West Gojjam Zone public hospitals, North West Ethiopia, 2019

\begin{tabular}{|c|c|c|}
\hline Items & Mean & SD \\
\hline $\begin{array}{l}\text { Practising new clinical approach is preferable than existing research findings (traditional method) for } \\
\text { clinical practice. }\end{array}$ & 3.2 & 1.17 \\
\hline Time allocation in a work schedule for use of research improves clinical decision-making practice. & 3.93 & 1.03 \\
\hline You accept comments provided by your colleagues which are based on established research findings. & 4.0 & 0.93 \\
\hline Total & 3.82 & 0.69 \\
\hline
\end{tabular}

in outpatient departments, and $84(13.3 \%)$ nurses in emergency wards. The other $108(17.1 \%)$ nurses were working in paediatric, neonatal intensive care unit, dental care unit, ophthalmology, tuberculosis care unit, injection room and expansion programme of the immunisation unit.

\section{Attitude of participants}

The Cronbach's alpha of the attitude-related questionnaire was 0.732 . The most important variables for attitude towards research utilisation were identified. First, participants desirably believed that research-based practice is fundamental to professional practice. Second, participants moderately believed that practising a new clinical approach is preferable than existing research findings (traditional method) for clinical practice. Participants' total mean score for attitude was taken as moderately favourable towards research utilisation (see table 2). About $63.25 \%$ of variance in attitudes towards research utilisation was explained by two variables, with eigenvalues of 2.8 and 1.0 for the first and second variables, respectively.

\section{Supporting factors for research utilisation}

The interitem correlation matrix of the supporting factors for research utilisation scale was 0.432-0.836. The internal reliability of the supporting factors for research utilisation scale was 0.913 . The item with the highest mean score was nursing and midwifery managers embracing research-based practice, with a mean score of 3.02. The total mean score for supporting factors for research utilisation indicated that there was poor support for research utilisation (see table 3).

\section{Self-efficacy in research utilisation skills}

The Cronbach's alpha for self-efficacy in research utilisation skills was 0.921 . The item with the highest mean score was that participants identified clinical problems according to currently available research findings. Using a checklist to assess a research article was the item with the least mean score. Statistical analysis of this item indicated that the total mean score for self-efficacy in research utilisation skills among nurses and midwives was considered poor (see table 4 ).

\section{Barriers to research utilisation}

The item with the highest mean score was difficulty in finding time to search for and read research articles. The item with the least mean score was inability to use research in their current clinical decision-making practices. The internal reliability of barriers to research utilisation scale was 0.966. Participants' total mean score for barriers to research utilisation showed moderate barriers to research utilisation (see table 5).

\section{Research utilisation}

The Cronbach's alpha for the 18 questions of the research utilisation scale is 0.956 . The total research utilisation scale score of the participants ranged from 19 to 77 . Of the participants, $70.4 \%$ (444) had a total research utilisation

Table 3 Supporting factors for research utilisation of nurses and midwives towards research-based practice in North Gondar and West Gojjam Zone public hospitals, North West Ethiopia, 2019

\begin{tabular}{|c|c|c|}
\hline Items & Mean & SD \\
\hline Given protected time to conduct research-based practice. & 2.89 & 1.12 \\
\hline Adequate training was given for nurses and midwives in research. & 2.96 & 1.14 \\
\hline There is support of access to a system for comprehensive literature searching. & 2.99 & 1.13 \\
\hline Total & 2.78 & 0.77 \\
\hline
\end{tabular}


Table 4 Self-efficacy in research utilisation skills of nurses and midwives towards research use in North Gondar and West Gojjam Zone public hospitals, North West Ethiopia, 2019

\begin{tabular}{lll}
\hline Items & Mean & SD \\
\hline Use a checklist to assess research articles. & 2.31 & 0.9 \\
\hline Evaluate the application of intervention and identify areas of improvement. & 2.51 & 1.04 \\
\hline Read a research report and have a general notion about its strengths and weaknesses. & 2.56 & 0.86 \\
You have been involved in monitoring and evaluation of clinical practice based on research findings. & 2.72 & 0.9 \\
$\begin{array}{l}\text { Apply an intervention based on the most applicable research findings. Evaluate the application of } \\
\text { intervention and identify areas of improvement based on research findings. }\end{array}$ & 2.74 & 1.11 \\
You have translated a clinical problem into a well-formulated clinical question. & 2.84 & 0.92 \\
$\begin{array}{l}\text { You analysed research guidelines before you have used these research findings in clinical decision-making } 3.04 \\
\text { practice. }\end{array}$ & 3.12 & 0.94 \\
Read a research report and have a general notion about its strengths and weaknesses. & 3.17 & 1.09 \\
You identify clinical problems according to currently available research findings. & 2.78 & 0.77 \\
\hline Total & &
\end{tabular}

score below 54, 29.4\% (186) had a score of 54-72, and $0.2 \%$ (1) had a score greater than 72 . The item with the highest mean score was informally discussing evidence from a research study, with a mean score of 2.91. The item with the least mean score was access to the Cochrane Database of Systematic Reviews. The total mean score of nurses and midwives in the research utilisation scale revealed that participants had poor research utilisation (see table 6).

\section{Assessment of composite variables score differences across} gender, years of experience, professional categories and age groups

An independent t-test was used to analyse the mean of two independent samples of men and women. One-way analysis of variance was used to analyse three or more age groups. The analysis indicated that the overall mean score for barriers to research utilisation among female nurses and midwives was higher than among male nurses and midwives $(p=0.002)$. However, significant difference was not observed in the overall score for attitude among men, women and age groups, and there was also no significant difference in terms of scores for barriers to research utilisation among the age groups of nurses and midwives.

Research utilisation scale score, barriers to research utilisation, supporting factors for research utilisation, selfefficacy in research utilisation skills, attitude and nursing/ midwifery work index were also examined among gender, age groups, years of experience and professional categories. Male nurses and midwives had higher scores in terms of supporting factors for research utilisation, compared with female nurses and midwives $(p=0.039)$. With regard to scores for barriers to research utilisation, a difference was seen in terms of years of experience of nurses and midwives $(p=0.047)$, with greater barriers to research utilisation identified in those with 11-34 years of experience. Nurses had better scores in research utilisation compared with midwives $(p=0.043)$. No difference was identified in scores for self-efficacy in research utilisation skills, supporting factors for research utilisation and nursing/ midwifery work index when compared among years of experience, two professional categories, age and gender.

Table 5 Barriers to research utilisation of nurses and midwives working in North Gondar and West Gojjam Zone public hospitals, North West Ethiopia, 2019

\begin{tabular}{lll}
\hline Items & Mean & SD \\
\hline Inability to use research in their current clinical decision-making practice. & 3.14 & 1.1 \\
\hline Inability to properly interpret the results of research studies. & 3.19 & 1.13 \\
\hline Insufficient resources (eg, equipment, materials) to use research findings. & 3.2 & 1.16 \\
\hline Difficulty in judging the quality of research papers and reports. & 3.24 & 1.14 \\
\hline Difficulty in determining the applicability of research findings. & 3.25 & 1.03 \\
\hline Inadequate understanding of terms used in research articles. & 3.3 & 1.18 \\
\hline Inability to implement recommendations of research studies into clinical practice. & 3.33 & 1.12 \\
\hline Inability to understand statistical terms used in research articles. & 3.35 & 1.11 \\
\hline Difficulty in finding time at workplace to search for and read research articles and reports. & 3.56 & 1.19 \\
\hline Total & 3.28 & 1.0 \\
\hline
\end{tabular}


Table 6 Research utilisation of nurses and midwives working in North Gondar and West Gojjam Zone public hospitals, North West Ethiopia, 2019

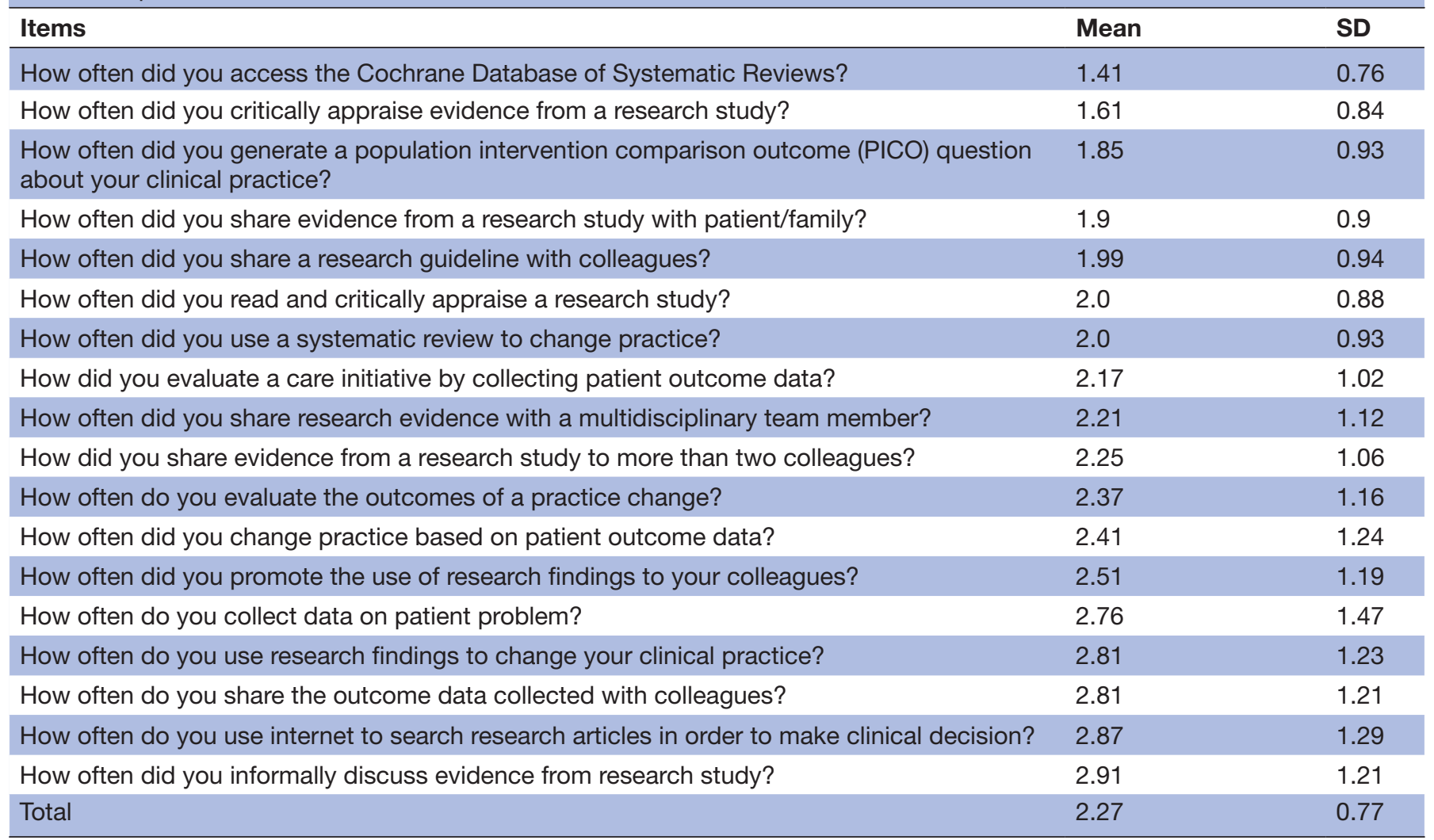

\section{Factors associated with research utilisation}

The correlation coefficient between research utilisation, self-efficacy in research utilisation skills, attitude of participants towards research utilisation, supporting factors for research utilisation, barriers to research utilisation, nursing/midwifery work index, position of nurses and midwives, marital status, adequate number of staff, nursing/midwifery work index and hospital's level of healthcare in bivariate analysis was -0.726 to -0.05 and 0.08 to 0.73 for negative and positive correlation respectively. Significant correlation was found at a $p$ value of 0.01 . Self-efficacy in research utilisation skills, attitude of participants towards research utilisation, barriers to research utilisation, supporting factors for research utilisation, hospital's level of healthcare and nursing/midwifery work index were found to be correlated with the outcome variable in the bivariate analysis and had statistically significant association with research utilisation.

This study found that the research utilisation scale score increased when self-efficacy in research utilisation skills scale score $(\mathrm{B}=0.86,95 \%$ CI 0.75 to 0.97$)$, attitude of participants towards research utilisation scale score $(\mathrm{B}=0.23,95 \%$ CI 0.07 to 0.38$)$, supporting factors for research utilisation scale score $(\mathrm{B}=0.4,95 \%$ CI 0.25 to 0.55 ) and nursing/midwifery work index scale score $(\mathrm{B}=0.07,95 \% \mathrm{CI} 0.04$ to 0.11$)$ of participants increased. However, research utilisation scale score decreased when barriers to research utilisation scale score $(B=-0.63,95 \%$
CI -0.72 to -0.54$)$ increased. The research utilisation scale score of nurses and midwives working in specialised hospitals ( $\mathrm{B}=4.5,95 \% \mathrm{CI} 2.13$ to 6.9$)$ was higher than the research utilisation score of nurses and midwives working in general and primary hospitals (see table 7). Moreover, factor analysis indicated that belief of research-based practice and trusted study findings increased research utilisation among nurses and midwives. The support provided by nursing and midwifery managers who embrace research-based practice and self-efficacy in research utilisation skills in identifying clinical problems according to currently available research findings also increased research utilisation. However, difficulty in finding time to search for and read research articles and reports as well as inability to understand statistical terms used in research articles were found to be barriers to research utilisation.

\section{DISCUSSION}

The results of this study showed poor research utilisation among nurses and midwives. However, nurses and midwives have activities that encourage them to use research in clinical decision-making practice. For example, participants informally discussed research articles to use as evidence for clinical decision-making. They also use internet to search for research articles in order to make clinical decisions. Similarly, other studies in Sweden, Norway, Turkey and China have shown low research utilisation $^{728-30}$ due to the possible lack of information on 
Table 7 Multivariable analysis of associated factors of research utilisation of nurses and midwives working in North Gondar and West Gojjam Zone public hospitals, North West Ethiopia

\begin{tabular}{|c|c|c|c|c|c|}
\hline \multirow[t]{2}{*}{ Independent variables } & \multicolumn{5}{|c|}{ Research utilisation } \\
\hline & B & St.B & $95 \% \mathrm{Cl}$ & $P$ value & Correlation \\
\hline (Constant) & 18.85 & & 12.28 to 25.43 & 0.000 & \\
\hline Barriers to research utilisation & -0.63 & -0.38 & -0.72 to -0.54 & 0.000 & -0.73 \\
\hline Attitude towards research utilisation & 0.23 & 0.06 & 0.07 to 0.38 & 0.004 & 0.31 \\
\hline Supporting factors for research utilisation & 0.4 & 0.16 & 0.25 to 0.55 & 0.000 & 0.67 \\
\hline Specialised hospitals & 4.5 & 0.15 & 2.13 to 6.9 & 0.000 & 0.12 \\
\hline Gender & -0.04 & -0.001 & -1.4 to 1.3 & 0.44 & -0.03 \\
\hline
\end{tabular}

B, unstandardised coefficients; St.B, standardised coefficients.

research utilisation and the lack of commitment to use research. The poor research utilisation finding could be explained as there was lack of support to apply the knowledge of nurses and midwives through reducing barriers of research utilisation in the healthcare. However, the findings of this study showed that about $29 \%$ and less than $1 \%$ of participants engaged in using research in decisionmaking in healthcare moderately and desirably, respectively. As the research findings have indicated, it was the effort of some nurses and midwives to use research without getting support from concerned bodies. The research utilisation score of nurses was higher than the the research utilisation score of midwives. This could be due to the lack of knowledge and skills to use research in clinical practice and the inadequate staff among midwives in the study setting compared with nurses.

Self-efficacy in research utilisation skills was important in increasing research utilisation in decision-making in healthcare. Although participants' self-efficacy in research utilisation skills was poor, the research utilisation scale score increased when self-efficacy in research utilisation skills increased. The study found that participants had hopeful activities such as identifying clinical problems according to currently available research findings and reading research reports. They have a general notion about the strengths and weaknesses of articles. The results of this study coincided with the findings of studies reported in Sweden, Norway, Singapore and Ethiopia. $^{831-33}$ This might be due to the similarity in support for self-efficacy in research utilisation skills of the participants in the study settings. The poor self-efficacy in research utilisation skills may be a result of nurses' and midwives' incompetency to perform their task according to research. The results of this study revealed that nurses and midwives had moderately positive attitude towards research utilisation; however, the participants use research in clinical practice to a lesser extent. Research utilisation scale score was higher among those who had higher attitude scale score. This finding coincided with the studies conducted in Norway, Singapore, Sweden,
China, Iran and Nigeria. ${ }^{52}{ }^{32-35}$ This could be due to the positive attitude of nurses and midwives that encourage them to use research. Positive attitude towards research utilisation could be vital to engage nurses and midwives in research utilisation activities. If nurses and midwives do not believe in the value of research, research utilisation can be difficult. At the same time, the poor attitude towards research utilisation indicated in this study might be due to poor self-efficacy in research utilisation skills.

The findings of this study revealed that when barriers to research utilisation scale score increased, research utilisation scale score decreased. Difficulty in finding time to search for and read research reports as well as inability to understand statistical terms used in research articles were the top barriers to research utilisation. These findings are in line with the studies in Singapore, Oman, Norway, Turkey and Iran. ${ }^{1427283336}$ This is due to work overload, lack of training in research utilisation and lack of awareness of nurses and midwives to use research findings in clinical decision-making practices. The findings of this study showed that majority of the participants had moderate or desirable barriers to research utilisation. Different factors such as lack of resources, judging the quality of research and other factors contributed to barriers to research utilisation. In order to increase research utilisation, overcoming all components which result in unsuccessful research utilisation is vital. In terms of gender, the score for barriers to research utilisation among female nurses and midwives was higher than among male nurses and midwives. This may be due to overlapping activities and lack of attention to support female nurses and midwives. A higher score in barriers to research utilisation was identified among nurses and midwives with 11-34 years of experience. This could be explained by young nurses and midwives' capabilities, which reduce barriers to research utilisation due to their recent university experience.

The findings of this study revealed that supporting factors for research utilisation scale score increased research utilisation scale score. Nursing and midwifery 
managers embracing research-based practice was the most important activity that increased research utilisation scale score. Similarly, other studies revealed that support for research utilisation among nurses and midwives improved many activities related to research utilisation and quality healthcare. ${ }^{3132} 37$ Lack of access to a system and lack of training and mentoring were also contributing factors to poor support for research utilisation. Training and mentoring can provide support to nurses and midwives to use valid and reliable literature within clinical settings and familiarise them with the Cochrane Library. Therefore, it is crucial to focus on the skills and knowledge of managers in providing support for research utilisation. In terms of supporting factors for research utilisation, male nurses and midwives obtained higher scores. Perhaps, males' empowerment to get support for research utilisation was better than females' empowerment and better priority was given to males than females.

Research utilisation scale score increased among nurses and midwives who had higher nursing/midwifery work index scale score than those who had lower nursing/ midwifery work index scale score. This finding is supported by a study reported in Spain. ${ }^{38}$ This could be explained by respondents with better nursing/midwifery work index score having the motivation to use research in clinical decision-making. Different factors contributed to poor nursing and midwifery work index. Creating good working environment and job satisfaction were important to research utilisation by improving nursing and midwifery work index.

Research utilisation scale score of nurses and midwives working in specialised hospitals was higher than research utilisation scale score of nurses and midwives working in general and primary hospitals. The findings reported by a study in Egypt also revealed that research utilisation varies in different study settings. ${ }^{39}$ This could be due to involvement of academic staff in using research in clinical decision-making in specialised hospitals, as well as the encouraging factors of research utilisation in the specialised hospitals of this study and the Assiut University Hospital in Egypt. The specialised hospitals were teaching hospitals which had adequate resources, training opportunities and staff with the highest educational status.

\section{Strengths and limitations}

The major strength of this study was the use of faceto-face interview techniques, which contributed to the $100 \%$ response rate. Risk of bias was reduced by ensuring the privacy of the interviewees. The study addresses research utilisation which is typically supported by reducing barriers to research utilisation, improving selfefficacy in research utilisation skills, increasing support for research utilisation, maximising positive attitude towards research utilisation, better nursing/midwifery work index and maximising hospital's level of healthcare. As far as our search for studies conducted in Ethiopia, this is the first study in the country to use validated instrument to assess nurses' and midwives' attitude, self-efficacy in research utilisation skills, barriers to research utilisation, supporting factors for research utilisation, nursing/midwifery work index and research utilisation.

The first limitation of this study was the possibility of social desirability bias as the study was conducted while nurses and midwives were working in the hospitals. Moreover, the information obtained from the study participants might be inflated or underestimated due to individuals with some interests. Second, this study was conducted in hospitals where more advanced human resource dynamics, quality medical service and well organisational structure were available. Hence, it is difficult to generalise to health centres and health posts. Finally, a limitation of this cross-sectional study was that qualitative design was not used to strengthen the findings.

\section{CONCLUSIONS}

This study revealed that research utilisation was poor. Selfefficacy in research utilisation skills, supporting factors for research utilisation, attitude towards research utilisation, barriers to research utilisation, nursing/midwifery work index and level of hospitals were found to be statistically significant predictors of research utilisation. Insufficient time to read research and inability to understand statistical terms used in research articles are the most common barriers to research utilisation.

Acknowledgements We are thankful to the data collectors and all nurses and midwives working in North Gondar and West Gojjam Zone public hospitals for their willingness to participate in the study. We also would like to express our deepest gratitude to Debre Tabor University for providing financial support and North Gondar and West Gojjam Zone health departments for providing information on the study population.

Contributors AHD and MMA contributed to the design of the study, conceptualisation, validation, visualisation and methodology, analysis and interpretation of findings, original draft and revision of the manuscript. Both authors read and approved the manuscript.

Funding This study was funded by Debre Tabor University. The funder is not listed in the FundRef Registry and there is no award number/grant number. The funding body had no role in the study design and collection, analysis and interpretation of data, and in writing the manuscript.

Competing interests None declared.

Patient consent for publication Not required.

Ethics approval Ethical approval for this study was obtained from the ethical committee of the Department of Midwifery, Debre Tabor University.

Provenance and peer review Not commissioned; externally peer reviewed.

Data availability statement Data are available upon reasonable request. The data sets used and/or analysed during the current study are available from the corresponding author on reasonable request.

Open access This is an open access article distributed in accordance with the Creative Commons Attribution Non Commercial (CC BY-NC 4.0) license, which permits others to distribute, remix, adapt, build upon this work non-commercially, and license their derivative works on different terms, provided the original work is properly cited, appropriate credit is given, any changes made indicated, and the use is non-commercial. See: http://creativecommons.org/licenses/by-nc/4.0/.

ORCID iD

Asrat Hailu Dagne http://orcid.org/0000-0002-4620-4047 


\section{REFERENCES}

1 Rosenberg W, Richardson WS, Sackett DL, et al. Evidence-Based medicine: how to practice and teach EBM. Churchill Livingstone, 2000.

2 Brown CE, Ecoff L, Kim SC, et al. Multi-Institutional study of barriers to research utilisation and evidence-based practice among hospita nurses. J Clin Nurs 2010;19:1944-51.

3 Matthew-Maich N, Ploeg J, Jack S, et al. Transformative learning and research utilization in nursing practice: a missing link? Worldviews Evid Based Nurs 2010;7:25-35.

4 Straus S, Tetroe J, Graham ID. Knowledge translation in health care: moving from evidence to practice. John Wiley \& Sons, 2013.

5 Wangensteen S, Johansson IS, Björkström ME, et al. Research utilisation and critical thinking among newly graduated nurses: predictors for research use. A quantitative cross-sectional study. $J$ Clin Nurs 2011;20:2436-47.

6 Higgins I, Parker V, Keatinge D, et al. Doing clinical research: the challenges and benefits. Contemp Nurse 2010;35:171-81.

7 Uysal A, Temel AB, Ardahan M, et al. Barriers to research utilisation among nurses in turkey. J Clin Nurs 2010;19:3443-52.

8 Dalheim A, Harthug S, Nilsen RM, et al. Factors influencing the development of evidence-based practice among nurses: a self-report survey. BMC Health Serv Res 2012;12:367.

9 Sadeghi-Bazargani H, Tabrizi JS, Azami-Aghdash S. Barriers to evidence-based medicine: a systematic review. J Eval Clin Pract 2014;20:793-802.

10 Kermanshahi S, Parvinian AM. Barriers to implementation of evidence-based care: viewpoints of nursing staff. Iranian Journal of Medical Education 2012;12:84-92.

11 Zwolsman S, te Pas E, Hooft L, et al. Barriers to GPs' use of evidence-based medicine: a systematic review. Br J Gen Pract 2012;62:e511-21.

12 Zwolsman SE, van Dijk N, Te Pas E, et al. Barriers to the use of evidence-based medicine: knowledge and skills, attitude, and external factors. Perspect Med Educ 2013;2:4-13.

13 Kajermo KN, Boström A-M, Thompson DS, et al. The barriers scale -- the barriers to research utilization scale: a systematic review. Implement Sci 2010;5:32.

14 Kocaman G, Seren S, Lash AA, et al. Barriers to research utilisation by staff nurses in a university hospital. J Clin Nurs 2010;19:1908-18.

15 Moreno-Casbas T, Fuentelsaz-Gallego C, de Miguel AG, et al. Spanish nurses' attitudes towards research and perceived barriers and facilitators of research utilisation: a comparative survey of nurses with and without experience as principal Investigators. J Clin Nurs 2011;20:1936-47.

16 Corchon S, Portillo MC, Watson R, et al. Nursing research capacity building in a Spanish Hospital: an intervention study. J Clin Nurs 2011;20:2479-89.

17 Severinsson E. Research supervision: supervisory style, researchrelated tasks, importance and quality - part 1. J Nurs Manag 2012;20:215-23.

18 Severinsson E. Discovering the value of research supervision. Nurs Health Sci 2010;12:400-1.

19 O'Byrne L, Smith S. Models to enhance research capacity and capability in clinical nurses: a narrative review. J Clin Nurs 2011;20:1365-71.

20 Henderson A, Winch S, Holzhauser K. Leadership: the critical success factor in the rise or fall of useful research activity. J Nurs Manag 2009;17:942-6.

21 Jeffs L, M Smith O, Wilson G, et al. Building knowledge for safer care: nursing research advancing practice. J Nurs Care Qual 2009;24:257-62.
22 Frenk J, Chen L, Bhutta ZA, et al. Health professionals for a new century: transforming education to strengthen health systems in an interdependen tworld. RevPeru-MedExpSalud Publica 2011;28:337.

23 Jamerson PA, Vermeersch $P$. The role of the nurse research facilitator in building research capacity in the clinical setting. J Nurs Adm 2012;42:21-7.

24 Gerrish K, Ashworth P, Lacey A, et al. Factors influencing the development of evidence-based practice: a research tool. J Adv Nurs 2007;57:328-38.

25 Melnyk BM, Fineout-Overholt E, Mays MZ. The evidence-based practice beliefs and implementation scales: psychometric properties of two new instruments. Worldviews on Evidence-Based Nursing 2008;5:208-16.

26 Kim C-W, Lee S-Y, Kang J-H, et al. Application of revised nursing work index to hospital nurses of South Korea. Asian Nurs Res 2013;7:128-35.

27 Farokhzadian J, Khajouei R, Ahmadian L. Evaluating factors associated with implementing evidence-based practice in nursing. $J$ Eval Clin Pract 2015;21:1107-13.

28 Stokke K, Olsen NR, Espehaug B, et al. Evidence based practice beliefs and implementation among nurses: a cross-sectional study. BMC Nurs 2014;13:8.

29 Zhou F, Hao Y, Guo H, et al. Attitude, knowledge, and practice on evidence-based nursing among registered nurses in traditional Chinese medicine hospitals: a multiple center crosssectional survey in China. Evid Based Complement Alternat Med 2016;2016:1-8.

30 Forsman H, Rudman A, Gustavsson P, et al. Nurses' research utilization two years after graduation--a national survey of associated individual, organizational, and educational factors. Implement Sci 2012;7:46.

31 Hadgu G, Almaz S, Tsehay S. Assessment of nurses' perceptions and barriers on evidence based practice in Tikur Anbessa specialized hospital Addis Ababa Ethiopia. AJNS 2015;4:73-83.

32 Boström A-M, Rudman A, Ehrenberg A, et al. Factors associated with evidence-based practice among registered nurses in Sweden: a national cross-sectional study. BMC Health Serv Res 2013;13:165.

33 Majid S, Foo S, Luyt B, et al. Adopting evidence-based practice in clinical decision making: nurses' perceptions, knowledge, and barriers. J Med Libr Assoc 2011;99:229-36.

34 Heydari A, Mazlom SR, Ranjbar $\mathrm{H}$, et al. A study of Iranian nurses' and midwives' knowledge, attitudes, and implementation of evidence-based practice: the time for change has arrived. Worldviews Evid Based Nurs 2014;11:325-31.

35 Ominyi JNO. Assessing the level of utilization of evidence-based nursing practice guidelines among nurse practitioners. International Journal of Nursing 2015;5:10-15.

36 Ammouri AA, Raddaha AA, Dsouza P, et al. Evidence-Based practice: knowledge, attitudes, practice and perceived barriers among nurses in Oman. Sultan Qaboos Univ Med J 2014;14:e537.

37 Sandström B, Borglin G, Nilsson R, et al. Promoting the implementation of evidence-based practice: a literature review focusing on the role of nursing leadership. Worldviews Evid Based Nurs 2011;8:212-23.

38 González-Torrente S, Pericas-Beltrán J, Bennasar-Veny M, et al. Perception of evidence-based practice and the professional environment of primary health care nurses in the Spanish context: a cross-sectional study. BMC Health Serv Res 2012;12:227.

39 Baiomy S, Khalek EM. Factors influencing effective implementation of evidence based practice among nurses in Assiut City hospitals, Egypt: a comparative study. J Nurs Health Sci 2015;4:11-19. 